\title{
Límites constitucionales
}

\author{
Alvaro Magaña*
}

"Por de pronto, una sola cosa y ella sencillísima: decir siempre y en todo caso la verdad, pero sobre todo cuando sea inoportuna".

Miguel de Unamuno

En este artículo, el autor expresa que en los últimos años, los valores y principios de la Constitución son ignorados, de allí la importancia de un Estado de Derecho que vigile el cumplimiento de los mandatos constitucionales. Desde 1950, la Constitución estableció objetivos para el bienestar general, tal como lo estipula el artículo 101 cuando se refiere a los "principios de justicia social". Asimismo analiza - desde el punto de vista jurídico - los distintos objetivos del acuerdo No 7, que pretende reformar el artículo 111 constitucional para que el Banco Central no conceda financiamiento al Estado.

* Ex profesor de la Facultad de Jurisprudencia y Ciencias Sociales de la Universidad de El Salvador. Director Ejecutivo del Programa Conjunto de Tributación OEA-BID-CEPAL (1961- 1965). Presidente del Banco Hipotecario de El Salvador (1965-1982). Director del Banco Central de Reserva de El Salvador (1976-1982). Presidente de la República de El Salvador (1982- 1984). 
El presente artículo es simplemente una manifestación espontánea y obligada ante la repetida y continua práctica —en los últimos años- de ignorar la Constitución, sus valores superiores y los principios fundamentales observados en la reciente legislación ordinaria, como en el caso de la nueva Ley Orgánica del Banco Central, y - lo que es más grave- en las reformas a la propia Constitución, como fue el caso del artículo 110 relativo a la privatización de servicios esenciales y más recientemente el acuerdo No 7 para reformar el artículo 111, que es materia del presente análisis.

Se ha insistido durante los últimos años en la importancia de un Estado de Derecho que vigile el estricto cumplimiento de los mandatos constitucionales, ya que la Constitución es un conjunto de normas jurídicas obligatorias. Por ello nos alegra (independientemente del contenido del veto) que en una reciente comunicación a la Asamblea Legislativa al vetar el Decreto No 135 relativo a la denominada condonación de la deuda agraria, el Presidente de la República hiciera un recordatorio fundamental: "Hoy la Constitución ha pasado a ser una verdadera norma jurídica y no cualquier norma, sino, precisamente la norma suprema, en la que se fundan todas las demás, lo que condiciona su validez de todas éstas".

Este estudio se concluyó el 14 de diciembre de 1997, a 49 años del Movimiento cívico-militar que inició, en verdad, un concepto moderno de Estado en el sentido propio de lo que es moderno, cuando se deja atrás el pensamiento económico liberal decimonónico de las Constituciones anteriores a 1950 y se aprueba una nueva Carta Magna en ese año, o sea, el documento histórico que estableció un Estado social y democrático de Derecho gracias al espíritu visionario de Reynaldo Galindo Pohl, Jorge Sol Castellanos, Oscar Osorio y tantos otros amigos de aquel tiempo - cuando mi padre me enseñó a estimar a los mejores - de una generación que señaló los derroteros de la historia del país por varias décadas.

Ahí quedó una legislación laboral de la seguridad social, financiera, tributaria, etc., que dio vigencia efectiva a los valores y principios incorporados a nuestra Constitución de 1950 , mantenidos en 1962 y 1983 y, en consecuencia, todavía forma parte de la Ley Superior vigente de El Salvador y de nuestro ordenamiento jurídico.

Lo anterior explica algunas razones para dedi- car este artículo al Dr. Jorge Sol Castellanos con respeto, admiración y aprecio. Lo hacemos, además, porque las ideas centrales y fundamentales de nuestro pensamiento se identifican plenamente con los valores y principios del ordenamiento constitucional que fue establecido en la Carta Magna de 1950. La contribución fundamental del Dr. Sol Castellanos se proyectó particularmente en la constitución económica recogida en la Ley Superior de ese año, tanto en el Título IX relativo al Orden Económico como en el Título VIII de la Hacienda Pública.

Quienes tuvimos el privilegio de conocer al Dr. Sol Castellanos y compartir con él esfuerzos, ilusiones y esperanzas, reconocemos en muchos preceptos de la Constitución la concreción de su pensamiento generoso y visionario que adversaron desde entonces quienes nunca entendieron que su pensamiento, que seguía el dictado de su conciencia, obedecía a que creía posible una patria mejor, lo cual debía ser digno de admiración en lugar de considerarlo peligroso. Quienes lo consideraron así no pueden ni podrán entender nunca que se recuerde con orgullo y agradecimiento a un hombre bueno, un amigo generoso, un ciudadano limpio que fue fiel a lo que creía.

Probablemente sean menos conocidas -que su participación en los trabajos de la Constitución de 1950 - otras contribuciones del Dr. Sol Castellanos a nuestra historia constitucional. Así, por Acuerdo No 80 del 17 de mayo de 1944, se dispuso nombrar una comisión "que tendrá por objeto formular un Proyecto de Constitución Política y Leyes Constitutivas que estará integrada por los Doctores Emeterio Oscar Salazar, Enrique Córdova, Miguel Tomás Molina, Miguel Angel Alcaine y Jorge Sol Castellanos", comisión que para agosto de 1944 ya había concluido un proyecto general que estaba siendo objeto de revisión. Para el II de agosto del mismo año, se enviaron al Ministerio de Justicia los tres primeros títulos que ya se habían revisado. El anteproyecto era realmente avanzado para la época pero, desafortunadamente, los acontecimientos políticos de octubre de 1944 terminaron por incorporar a nuestro ordenamiento constitucional conceptos fundamentales, recogidos seis años después por la constitución de 1950.

Cuando recordamos al Sr. Sol Castellanos pensamos que es desafortunado para nuestro país no conocer bastante los valores que hemos tenido en el campo del Derecho o de la Economía, para el 
caso, que además luvieron un comportamiento estricto, ignoraron consideraciones personales y que en su manera de actuar no influyeron los intereses del grupo social al que pertenecía. Y es que una sociedad no puede avanzar sin el empuje que proviene de estas personas que, al nadar contracorrientc, actúan con una ejemplaridad determinada simplemente por dignidad, y que nos alerta y ayuda para defendernos mejor de la presión de quienes tratan de imponer opiniones y comportamientos con los que disentimos.

La participación del Dr. Sol Castellanos en julio de 1950 -cuando se discutía en la Comisión de la Asamblea Nacional Constituyente, encargada de elaborar el proyecto de Constitución Política de la República y sus aportes e intervenciones en las discusiones - confirman nuestro aserto porque él tenía claro el equilibrio necesario que debe haber entre el bienestar económico, la cohesión social y la democracia.

Ralf Dahrendorl -en un trabajo titulado " $\mathrm{La}$ cuadralura de un círculo"- planteaba conceptos fundamentales sobre las combinaciones necesarias que comenta Don Joaquín Estefanía en un reciente arlículo (El País. Edición Internacional, 17 de noviembre de 1997 , p. 9), cuando dice que pueden ser "¿desarrollo económico en libertad política pero sin cohesión social? O, ¿desarrollo económico y cohesión social carentes de libertad política? o bien, ¿libertad política y cohesión social — si fuera posible aunarlas - en la pobreza?". Estefanía nos recuerda que las sociedades que podrían considerarse más avanzadas habían logrado en su mejor momento combinaciones en que, por ejemplo, eran: "Economías que no se limitaban a ofrecer una vida decente para muchos de sus ciudadanos, sino que parecían hechas expresamente para crecer y ofrecer oportunidades incluso a aquellos que aún no habían alcanzado la prosperidad". Además, la combinación incluía el respeto al Estado de Derecho y la participación política con la alternancia, que es la democracia.

Era - dice Joaquín Estefanía- la utopía factible; cran las oportunidades económicas, la sociedad civil y las libertades políticas. Eso fue lo que empezó a terminar con el neoliberalismo y su modernización y globalización. La pobreza creciente nos lleva, entre otras cosas, a nuevos tipos de exclusión social, como califica Dahrendorf a esas minorías que llaman lumpen (¿un 5 por ciento? ¿un 10 por ciento de la población?), que es lo que
Viviane Forrester llama el horror económico y Vargas Llosa denomina superchería sin fundamento.

Por todo lo anterior, debemos hacer alusión a una cuestión de gran importancia, que seguramente hubiera merecido la atención del Dr. Sol CasteIlanos. Desde diciembre de 1995, en un trabajo fechado el 28 de diciembre —día de los Santos Inocentes por cierto- sobre el premio Nobel en Economía de ese año, planteamos nuestras reservas y serias dudas sobre la forma y calendarización de las políticas económicas del neoliberalismo que se adoptaron en nuestro país al iniciarse una serie de medidas desde 1989 , cuando comenzaron a reducir los impuestos de importación en forma significativa y eliminar la Junta Monetaria, que aseguraba la participación del Estado en las decisiones fundamentales de la política monetaria, cuya orientación no puede ni debe ser independiente de la política fiscal y, en general, de la política económica. Esta corresponde exclusivamente al Estado y correspondería aun después de que la presente legislatura llegara a ratificar el acuerdo No 7 de la reforma al artículo 111 constitucional.

Antes de referirnos específicamente a nuestros scñalamientos, es importante recordar lo que hemos puntualizado de manera reiterada. Así, en un reciente trabajo volvimos a insistir cuando dijimos: "que los principios constitucionales deben entenderse y consecuentemente interpretarse, como parte de un sistema, de un programa constitucional que entre nosotros desde 1950, significó un cambio fundamental de nuestro régimen superior al establecer un Estado social y económico de Derecho, ratificado en 1962 y en 1983...." ("Los princi-

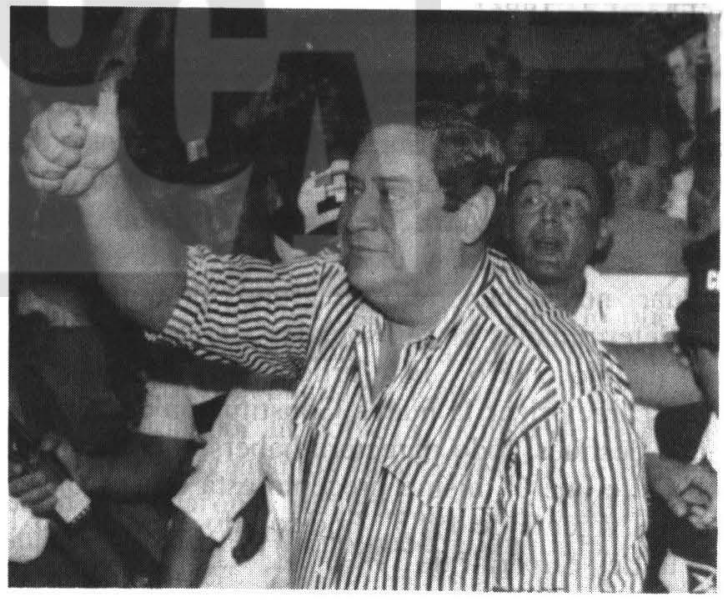


pios constitucionales presupuestarios". Cuademos IEJES, No 15, noviembre, 1996). Debemos decirlo claramente - ese trabajo lo hicimos con palabras del profesor Manuel Aragón Reyes-, pues la Constitución de 1950 significó abandonar la "economía libre" y adoptar un modelo de economía intervenida, que requiere del establecimiento - por la Constitución- de limitaciones para los particulares porque —como decía el profesor español citado-, el nuevo modelo requiere de mayor protagonismo de los poderes públicos (Libertades econónicas y Estado social, McGraw Hill: Madrid, 1995, p. 5 y ss.).

Ese es nuestro ordenamiento constitucional vigente y mientras no lo cambiemos, por lo menos debemos respetarlo. En el mismo estudio señalamos: "Esa es precisamente la característica de la filosofía y de la orientación fundamental de la Constitución de 1950, ratificadas en 1962 y aún vigentes al reafirmarlas nuestra constitución actual de 1983. Los conceptos transcritos se aplican sin ninguna duda a la experiencia salvadoreña. Veamos.

La exposición de Motivos de la Constitución de 1950 es calegórica cuando al referirse al arlículo 2 claramente dice: 'Esta disposición que algunos tacharán de poco práctica, puede dar base para una amplia, constructiva y revolucionaria legislación. Aquí se per-

fila con singular vigor, el Estado con que la constitución de 1950 sustituirá al Estado individualista y liberal de 1886'.

Antes de esa conclusión, el constituyente de 1950 había dicho: 'Este artículo consagra, en el aspecto jurídico, los fines del Estado promotor del bien público. De esta manera, los derechos meramente formales que reclamó la Revolución Francesa se completan, y el Estado queda obligado a actuar, no en beneficio de grupos dominantes ni de delerminadas clases sociales sino en beneficio del pueblo entero. Este artículo es indispensable para caracterizar la nueva Constitución'. Cuarenta años después, todo parcciera haberse olvidado, no obstante que el mismo precepto está en la Constilución vigente de 1983" (inciso 2do del artículo 1 de la Ley Superior de 1983).
Creemos firmemente que nuestros planteamientos anteriores tienen sustentación en una realidad que no puede ignorarse, pues no se trata sólo de la Constitución Política del Estado, sino de la Constitución Jurídica. Y, por ello, porque también es el caso de El Salvador, coincidimos con lo que dice Manuel Aragón Reyes: “... en el terreno de la economía la Constitución de ahora [frente a la Constitución del siglo pasado] amplía considerablemente su campo normativo estableciendo los principios rectores del sistema económico y determinando las posiciones que en ese sistema ocupan los sujetos privados y los poderes públicos. La regulación de la economía ha pasado a ser parte, pues, de la materia constilucional". Y no hace falta decir más.

Más adelante señalamos que todavía no se ha hecho un estudio serio y objetivo en nuestro país sobre el neoliberalismo. Pero es importante considerar -y no quisiéramos que se olvidara si se llegara a hacer algún día - que no sólo debemos considerarlo y analizarlo, como una corriente del pensamiento económico, sino más bien como una estrategia económica. Pero, además -y esto es lo importante-, no podemos ignorar que también es una estrategia política y obviamente ideológica. (Ver Siempre, Mćxico, No 2311,2 de octubre de 1997, p. 33.) Lo anterior es porque se ha pretendido despojar a la política económica de los últimos años de todo tinte ideológico y partidista, y así sc presentan las medidas como principios técnicos básicos, fundamentales, que deben discutirse con rigor científico. Por cllo, cualquier planteamiento distinto a csas políticas económicas carece de sustento, y lo menos con que se puede denominar a quien adopte posiciones críticas de ellas es de desfasado. En verdad, todo lo que alecte $\mathrm{e}$ interese a la sociedad es en esencia polílico y la discución del modelo económico a adoptarse, sin duda, se sitúa en el terreno político c ideológico.

Desde el punto de vista económico, el factor determinante que explica todas las medidas y los cambios adoptados recientemente es la globalización. Para alcanzar lo que el capital financiero transnacional deseaba, era necesario disminuir los impuestos proteccionistas de los países que inicia- 
han su desarrollo económico - a los cuales nos identificaron como sur - para abrir nuestros mercados, a pesar de que con ello dañaran las incipientes industrias que nacieron en el marco del Mercado Común Centroamericano que todavía tenía imporlancia, pues además nos hubiera servido para encauzar en mejor forma nuestra incorporación a la golobalización. Después viene la privatización "justilicada" por la política de no intervención estatal sustentada en el dogma del dejar hacer, dejar pasar: así, se abricron las puerlas para el saqueo y, por tanto, el Estado deja de ser promotor de la economía, y el desarrollo descansa en la acción de la iniciativa privada. Esta postura no es téenica se quicra o no- es política y hasta ideológica en lat medida en que es un retorno al liberalismo. De igual modo, es política e ideológica la posición de quienes pugnan que mediante el impulso de los programas sociales y la justicia distributiva es como se alcanza un desarrollo más generalizado que no sólo benelicic a una minoría.

Con las políticas recientes, supuestamente creamos todas las condiciones para que el esquema neoliberal nos conduzea al crecimiento sostenido y assí seguimos, sólo para cilar un ejemplo, las políticas monetarias de altas tasas de interés como medida antiinflacionaria ( $\sin$ importar lo que le pase a la inversión, aun cuando ésta debería tener rendimientos del 30 al 40 por ciento). Pero eso no tiene importancial cuando los niveles de inflación son bastante satisfactorios para ef Fondo, incluso si, además, para lograr el ideal de un dígito, se disminuye el gasto público social, porque lo único importante es cvitar un délicit presupuestario por la inflación.

El problema de las finanzas públicas — según quienes preparan el presupuesto- se limita al equilibrio presupuestario, que es determinante de la política tributaria y del gasto público. Ello explica que ignoren que los ingresos públicos y los gastos constituyan un medio efectivo para contrarrestar la desigualdad. Por eso es motivo de escándalo la solicilud de un aumento en el gasto social o la disminución de IVA. Se olvida también que los ingresos del Estado dependen del comportamiento de la economía; así, cuando ésta crece aquellos aumentan. Pero ahora, con el neoliberalismo, el Eslado se replicga a los lineamientos vigentes en el siglo XIX e incluso del XVIII, pese a que el informe décimo de la UNCTAD - presentado en sepliembre del año pasado sobre los 48 países menos

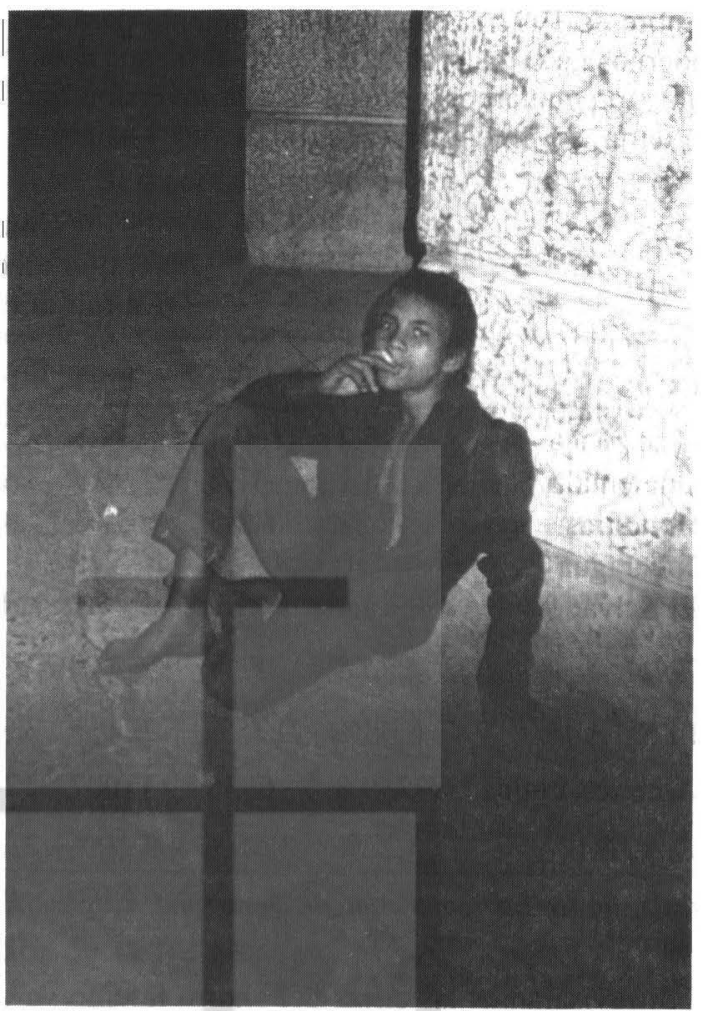

adelantados (PMA) - señala que alrededor de la mitad de ellos experimentaron un significativo retroceso en su avance en la última década. El mismo informe subraya que los PMA: " tendrán que dar prioridad a su frecuentemente descuidado sector agrícola si quieren alcanzar y mantener altas lasas de crecimiento". Tal vez ahora le crean a nuestros agricultores cuando lo lean nuestros técnicos. Por otra parte, como señalamos en otra oportunidad, el sistema tributario ignora que la redistribución se terminó al disminuir o suprimir los impuestos justos y establecer nuevos impuestos sobre el consumo, como el IVA, hecho que planteamos en un trabajo titulado "¿El finn de la redistribución?" (Derecho, Universidad de El Salvador, No 2, abriljunio, 1995).

Sería largo seguir insistiendo sobre lo que ha provocado esta situación, ahora que al fin comenzamos a observar una significativa y generalizada preocupación por la pobreza incluso de parte de los mismos organismos financieros que la fomentaron o ayudaron a aumentarla y que, ante los resultados evidentes, ya no pueden ignorarla. (Véase la revista $T I M E$, Edición internacional, 8 de di- 
ciembre de 1997.) Este no es el momento para extendernos en estos problemas, pero al menos deberíamos preguntamos: ¿dónde está la inversión que nos daría ese crecimiento sin inflación? Las cifras siguientes (públicadas en El Mundo del 14 de noviembre de 1997, p. 12) son muy reveladoras. (ver Cuadro 1.)

\begin{tabular}{lrrrrrrrrrr} 
& \multicolumn{1}{c}{$\begin{array}{c}\text { Cuadro 1 } \\
\text { Inversión directa extranjera } \\
\text { (En millones de dólares) }\end{array}$} \\
\hline País & 1989 & 1990 & 1991 & 1992 & 1993 & 1994 & 1995 & 1996 & Total \\
\hline Costa Rica & 95.2 & 160.4 & 172.8 & 221.6 & 244.4 & 292.9 & 390 & 396 & 1973.3 \\
Guatemala & 76.2 & 47.6 & 90.7 & 94.1 & 142.5 & 65.1 & 75.3 & 87.1 & 678.6 \\
Honduras & 51 & 43.5 & 52.1 & 47.6 & 26.2 & 34.8 & 50 & 75 & 380.2 \\
Nicaragua & 0 & 0 & 0 & 15 & 38.8 & 40 & 70.4 & 75 & 239.2 \\
El Salvador & 14.4 & 1.9 & 25.2 & 15.3 & 16.4 & 0 & 38 & 25 & 136.2 \\
Total & 236.8 & 253.4 & 340.8 & 393.6 & 468.3 & 432.8 & 623.7 & 658.1 & 3407.5 \\
El Salvador & $6.08 \%$ & $0.75 \%$ & $7.39 \%$ & $3.89 \%$ & $3.50 \%$ & $0.00 \%$ & $6.09 \%$ & $0.00 \%$ & $4.00 \%$ \\
América Latina & 7359.8 & 6936 & 11007 & 12021 & 11877 & 21062 & 23048 & 35680 & 128991 \\
C.A./A.L. & $3.22 \%$ & $3.65 \%$ & $3.10 \%$ & $3.27 \%$ & $3.94 \%$ & $2.05 \%$ & $2.71 \%$ & $1.84 \%$ & $2.64 \%$ \\
\hline
\end{tabular}

Fuente: Banco Interamericano de Desarrollo, Progreso Económico y social, 1997.

Si revisáramos las cifras del ahorro interno veríamos que son igualmente desalentadoras; de igual modo, los problemas presupuestarios en lo relativo a los ingresos públicos, actualizados el pasado mes de octubre, deberían ser justificaciones suficientes para revisar y reorientar nuestras políticas económicas, en lugar de dejarlas en manos de quienes sirven intereses foráneos o de grupos que son en definitiva los únicos favorecidos. ¿Por qué el Estado no toma el control de la política crediticia y estimula de verdad al sector agrícola? ¿Por qué no orienta su política cambiaria para estimular las exportaciones? ¿Por qué no orienta la política monetaria para cumplir su obligación constitucional?, cuando todos sabemos que la maquila es una inversión golondrina de la que no podemos depender. En este orden de ideas solamente tratamos - en el presente artículo que no es un estudio económico sino jurídico- de plantear que debe darse cumplimiento a la Constitución que desde 1950 estableció objetivos para el bienestar general, tal como lo estipula el artículo 101 cuando se refiere a los "principios de justicia social" y, de la misma forma, a los artículos 1 y 2 , por ejemplo.

En relación con el artículo 101 constitucional (artículo 135 de la Constitución de 1950), el cual establece que "el orden económico debe responder esencialmente a principios de justicia social que tiendan a asegurar a todos los habitantes del país una existencia digna del ser humano", debo confesar mi satisfacción cuando leí los conceptos vertidos por los representantes del pueblo salvadoreño, al discutirse la aprobación de este precepto constitucional en la sesión de la Asamblea Legislativa del 22 de julio de 1983. Así, un diputado — $\sin$ lugar a dudas con ideas progresistas- dijo en esa oportunidad, refiriéndose a dicho artículo:

"Aquí se han vertido algunas opiniones al respecto de lo que es el significado de las primeras tres líneas de este artículo, que dice que el orden económico debe responder especialmente a principios de justicia social, que tiendan a asegurar a todos los habitantes del país, una existencia digna del ser humano".

"Yo creo que los conceptos filosóficos que están vertidos en este párrafo, son indiscutiblemente, de una gran importancia y lo que es más importante aún, es que durante las discusiones que tuvimos en la mesa, a nivel de la comisión interpartidaria, así fue comprendido. Todos estuvimos total y absolutamente de acuerdo en esos principios y todos estamos totalmente de acuerdo también, en hacer 
todo lo que sea necesario, para que este principio no solamente quede plasmado en estos tres renglones, sino que también se logre el propósito".

A 14 años después, lo único que podemos agregar es que sobran los comentarios. Y si se ha intentado prohibir el financiamiento del Banco Central al Estado para lograr la vigencia del precepto, como dicen los considerando del acuerdo No 7 , probablemente será un poco difícil lograr dicho propósito después de casi cinco años de negar ese financiamiento por la Ley Orgánica.

Con todos los cambios que se suscitan, no me cabe la menor duda de que tenemos motivos sobrados para reflexionar

- cuando leemos lo que ocurre en Asia, de las hambrunas en Africa, el desempleo en Argentina- sobre el cambio de actitud de los países más desarrollados en cuanto a su ayuda financiera a los países pobres, incluyendo la ayuda humanitaria. Todo esto obliga a replantear algunas cosas $y$ pensar en algunos cambios para la próxima década. Es interesante recordar que el Club de Roma ha fijado su atención en esa peligrosa realidad y tendencia, lo cual ha sido señalado en dos informes cuyos títulos son bastante expresivos: "La revolución de los desamparados" y "el escándalo y la verguienza de la pobreza". En ellos se advertía - según palabras de Ricardo Diez Hochleitner, Presidente del Club de Roma- que quien sabe si un día, haciéndose eco de aquel grito ya lejano de " Proletarios del mundo uníosi", que tanto daño y dolor ha traído, no surgirá otra proclama, esta vez: "Pobres del mundo uníos, que haría estremecer a los olvidados de la tierra y temblar de pavor a los privilegiados".

También debemos meditar con mucha atención en las palabras que pronunciara Fernando Enrique Cardozo - durante la reciente y quizás tardía visita del presidente Clinton a Suramérica- cuando dijo públicamante que el gran proyecto de Brasil se llama Mercosur, aunque esté dispuesto a más largo plazo a compartir el proyecto ambicioso de un gran mercado "de Alaska a Tierra de Fuego". También fue explícito -el presidente de la mayor potencia presente y futura en el subcontinente- al declarar que "el nuevo orden global no puede ser impuesto, sino compartido".

$Y$ es que el presidente brasileño tiene mucha razón. Si recordamos que hace algún tiempo, en la misma semana, M. Camdessus, Director del Fondo Monetario Internacional, y Sebastián Edwards, entonces del Banco Mundial, dijeron que en el marco de la reestructuración neoliberal, la única posibilidad de crecimiento del empleo era la "flexibilización laboral", que dicho en palabras menos sofisticadas significa abaratar el costo de la mano de obra, es decir, eliminar los derechos y conquistas laborales. Flexibilización que, por cierto, no ha

funcionado en Argentina donde continúan los altos niveles de desocupación. Además, en los primeros años de esta década, recuerdo que el PREALC (Programa Regional de Empleo de América Latina y el Caribe) señaló que cuatro de cada cinco empleos creados en la región pertenecían al sector informal o de la pequeña empresa, que son los sectores que tienen las peores condiciones laborales.

Por cierto, el mismo Sr. Edwards, en un artículo titulado "El bajo rendimiento de América Latina" (Archivos del presente, Buenos Aires, No 8, abril-mayo-junio, 1997) hizo los importantes señalamientos siguientes: "El crecimiento económico de la región es desalentador en tres aspectos. Según el Banco Mundial es mucho más bajo que el promedio histórico de la región de 6 por ciento desde 1965 hasta 1980; es considerablemente más bajo que las tasas de crecimiento de Asia Oriental, que se han convertido en un crecimiento sostenido, y se encuentra muy por debajo de la tasa de crecimiento mínima requerida para reducir la pobreza, 3.4 por ciento anual". Y continúa: "El rendimiento de América Latina también ha sido desalentador desde el punto de vista social. En la mayoría de los países, las condiciones sociales, particularmente la pobreza, no han mejorado. En muchos países, el desempleo ha aumentado abruptamente, haciendo necesario formular la pregunta de si estas economías de mercado crearán empleos 
con la suliciente rapidez como para absorber una olerta laboral creciente. En 1996, el PIB aumentó un promedio de 3.1 por ciento en la región, y se espera que para 1997 ascienda a 4 por ciento. A pesar de que esta recuperación scría una mejora considerable con respecto al rendimiento de 1995 , no es suficiente para el largo plazo".

En los últimos años, los categóricos cuestionamientos de las políticas neoliberales son demasiado repetidos y así, en un artículo titulado "El liberalismo ¿cs justo o injusto?", cuyo autor es JeanPaul Fitoussi, prolesor del Instituto de Estudios Políticos de París, scñala: "El incremento de la desocupación y la pobreza en nuestros días, que en mi opinión resulta de la aplicación demasiado dogmática del principio del liberalismo - porque antes el riesgo era el socialismo, pero ahora, ¿cuál es el riesgo"? - desequilibra csa tensión, y podría llevarnos a retomar en sentido contrario el curso de la historia". Inmediatamente después puntualiza categóricamente: "No me parece que la solución para cl más grave de los problemas que debe afrontar una democracia en liempos de paz - la desocupación masiva- consista en resignarse a un temible aumento de desigualdades y al desmantelamiento de nuestro sistema de protección social. Por el contrario, la solución está mucho más en la cohesión, y no sólo por razones morales sino por razones de elicacia. En todo caso traté de demostrar que la equidad no debe ser una preocupación secundaria, una venda para cubrir las heridas causadas por las circunstancias de la eficacia, sino que es la condición misma de la eficacia". (Archivos del Presente, Buenos Aires, No 8, 1997.)

No podríamos decir, sin faltar a la verdad, que no queríamos referirnos a lo que es central, pues no dudo que si me hubiera tocado haber vivido en el siglo pasado hubiera sido liberal, así como fueron algunos de mis antecesores de familia. $Y$ es que no podemos olvidar que el liberalismo tuvo su época de gloria cuando se enfrentó al absolutismo monárquico —defendía el sufragio, la libertad, etc. Por eso pensamos - junto con José Ortega Spottomo- que el siglo XIX fue un siglo largo que empezó en 1789 con la Revolución Francesa y concluyó después de 1900. También compartimos el pensamiento del mismo autor en cuanto a que el siglo $\mathrm{XX}$ es un siglo corto que comenzó al concluir el XIX y se acabó en noviembre de 1989, cuando cayó el muro de Berlín —o a lo mejor quizás tarda en morir.
Pero podemos pensar que el liberalismo, en su tiempo, fue bueno - ya se sabe y no hace falta recordarlo-, y que las segundas partes no son buenas y terminan quedándose como una pobre imitación de las primeras. Veamos realmente qué es lo que está ocurriendo cuando se pretende, por cjemplo, seguir a ultranza el ideal de la liberlad de empresa que sólo sería posible si se cumplicran los principios de igualdad en la competencia, la cual está impedida para las empresas medianas y pequeñas. Veamos cuál es la experiencia de lo acontecido. Qué es lo que observamos después de una década de neoliberalismo. Encontramos todo lo contrario: concentración del poder y de la riqueza entre menos. Así, a la sombra de la libertad de empresas se terminan las empresas medianas y pequeñas, pero eso lo debemos ignorar en aras de la globalización. No voy a decir que económicamente sea correcto o incorrecto, pero sí pucdo afirmar que es contrario a la Constitución, por lo menos en El Salvador.

Este artículo analiza distintos aspectos del propósito del acuerdo No 7, que pretende reformar el arlículo 111 constitucional para que el Banco Central no conceda financiamiento al Estado. El objetivo es evitar que un déficit fiscal, al ser financiado por el Banco Central, genere presiones inflacionarias que en la actualidad no podemos ni siquiera imaginar. Nuestro estudio, orientado básicamente desde el punto de vista jurídico, cuestiona esa pretendida independiencia que - según algunos- el Banco Central debería tener.

Queremos destacar que si bien es cierto que no podríamos cuestionar la conveniencia de cierta autonomía de la banca central, no debe confundirse con una independencia que sin duda tiene efectos negativos, como lo prueba nuestra propia experiencia y que ahora tratan de ignorarse con una serie de maniobras de distracción o repitiendo machaconamente que todo está bien - lo cual, pienso, que ni ellos mismos lo creen. Si la autonomía puede justificarse para lograr una conveniente neutralidad de los bancos centrales que dificulte las presiones políticas partidistas, eso sólo sería una parte del problema.

La verdad es que los grupos de intereses (en connivencia con el gobierno en muchos casos) toman, en la realidad, el control de la banca central, y los resultados, sin duda, son peores todavía cuando el gobiemo lo ha tenido. En todo caso, le guste 
a quien le guste, el Gobierno de El Salvador dirigió elïciente y responsablemente por varias décadas la Banca Central para cumplir con lo que manda la Constitución.

A continuación presentamos nuestras reservas de naluraleza económica y nuestras discrepancias (lesde el punto de vista jurídico. Dejamos que el lector pondere nuestros planteamientos, los cuales hemos tratado de lundamentar conforme a nuestro enfoque jurídico: el Derecho Constitucional y el Derecho Administrativo. Asimismo queremos recordar que Joayuín Estelanía, a quien citamos antes, decía: "El Estado liberal

\section{El PREALC (Programa Regional} de Empleo de América Latina y el Caribe) señaló que cuatro de cada cinco empleos creados en la región pertenecían al sector informal o de la pequeña empresa, que son los sectores que tienen las peores condiciones laborales. democrático devino en

Estado social democrático cuando sc aunaron la ciudadanía y la soliclaridad. Ahora hay una marcha atrás; existe una extraña semejanza en algunos aspectos entre el línal del siglo XIX y el término de este milenio: el individualismo rampante ante los problemas sociales. Entonces era el manchesterianismo; hoy, el pensamiento neoliberal devenido en pensamiento único. Ayer, la reacción lue el colectivismo. ¿Y ahora? ¿Dónde está el equivalente al movimiento socialista de antaño, tan amplio?"

Mientras tanto, como ya ha sido señalado, el mercado sustiluye a la democracia e inevitablemente pensamos en el modelo isiálico —que nadie de sus antiguos entusiastas ha salido a defender- cuando desde a mediados del año empezaron a entrar en cri- sis. Lo mismo ha pasado en América Latina, nos presentaron a México como el máximo ejemplo antes de lo ocurrido en 1994, cuando lo que llamaron "efecto tequila" llegó hasta a ser "efecto tango", y en 1997 fue "¡crisis dragón!”

Para finalizar, y parafraseando a Gunter Grass, diremos que el capitalismo se considera victorioso contra el comunismo $y$, certeramente, dice el gran intelectual alemán refiriéndose a Europa frente al comunismo, "y como todos los vencedores en la historia hace tonterías. Vencer parece una vía segura a la estulticia". Y agrega "Hemos dado vía libre al capitalismo, que desde una cierta civilización vuclve a actitudes del siglo XIX". Por cso señalamos que en el neoliberalismo hay una vertiente política que se corresponde con la económica, y ambas obedecen a los mismos intereses y a los mismos fines. También puntualizamos que se ha querido despojar a la política económica de todo tinte ideológico o partidista.

Pero debemos reiterar, y es importante desta-

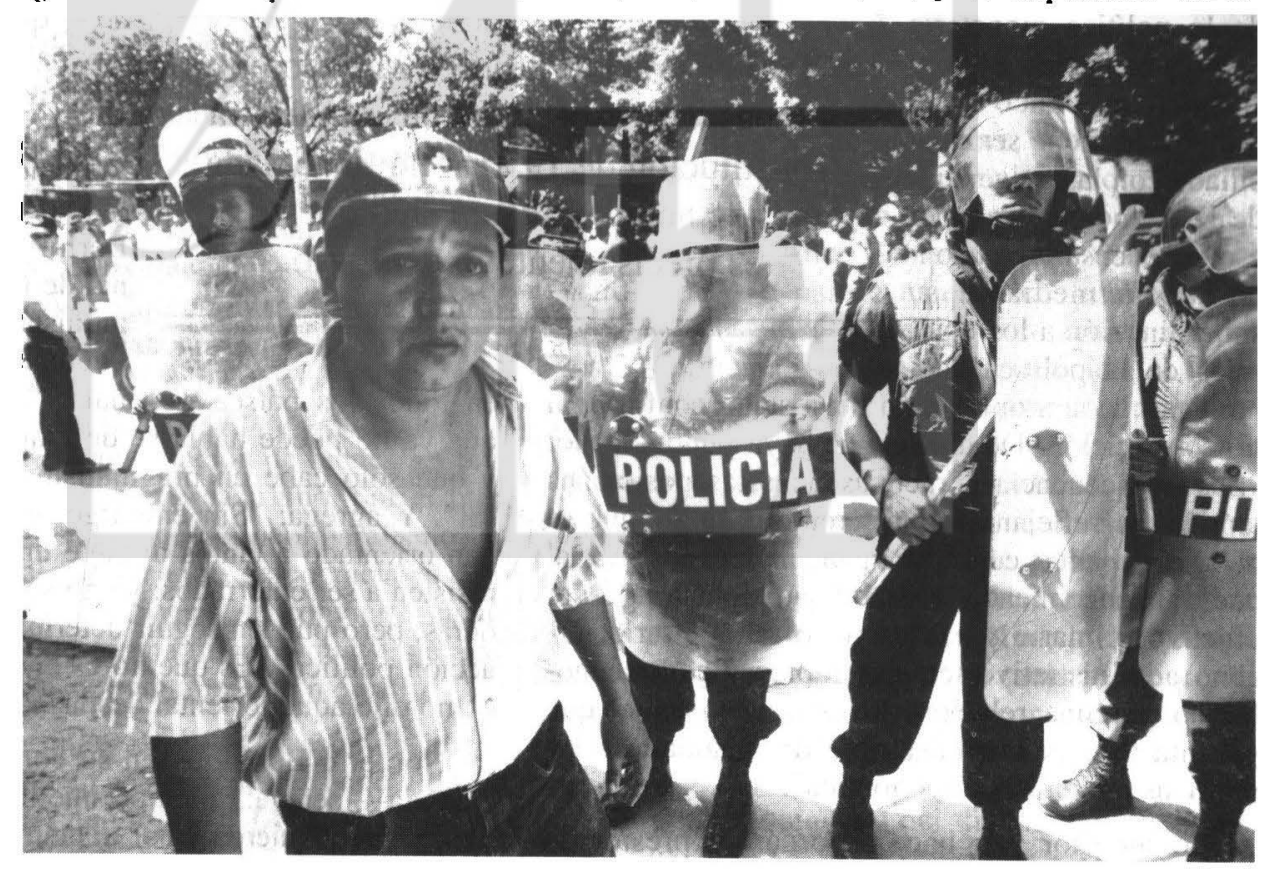


carlo, que el ordenamiento jurídico salvadoreño - pensando especialmente en nuestra Constitución de 1950 - no tiene nada de neoliberalismo sino que es precisamente lo contrario. Porque, como lo hemos señalado en otras oportunidades, esa no es la orientación política, es decir, el indirizzo, como dicen los tratadistas italianos, que subyace en todos los preceptos de la Ley Superior desde 1950 y que debería estar en todo nuestro ordenamiento jurídico.

Al decir que en el neoliberalismo existe una vertiente política que se corresponde con la económica, recordamos al profesor de Cecco y que A. Salerno resume así "Se ha puesto de relieve el intento de las fuerzas políticas dominantes de 'despolitizar' el problema de la inflación, trasladando al banco central, configurado a propósito como un órgano apolítico e independiente, la solución de un problema de naturaleza claramente política. Mediante la encomienda de la estabilidad monetaria (transformada en ciencia positiva y objetiva, y privada de toda connotación política) a un banco central, caracterizado por una estructura estrictamente técnica, los órganos políticos trasladan la responsabilidad de sanear una economía enferma y una inflación elevada, que ellos no han podido solucionar, a órganos políticamente irresponsables frente a los electores".

\section{Dadas las exigencias} de la política monetaria -cuya ejecución es confiada a un Banco Central-, ésta debe ser conciliada con las exigencias de la economía real; por eso es necesaria su concordancia mediante su subordinación a los objetivos de la política económica que son obligación del Estado conforme a la Constitución. De ahí que se haya puntualizado: "Las consecuencias prácticas de estas posiciones teóricas se reflejan en la diferente posición que se otorga al banco central: órgano independiente, al que se le encomienda la estabilidad monetaria como objetivo primario y exclusivo: o, al contrario, órgano administrativo técnico atípico, ligado al gobierno por una relación dialéctica constante, que permita la conciliación en pie de igualdad de las políticas monetaria y cconómica".

Lo anterior nos hace recordar al presidente
Sanguinetti —en la reciente Reunión de Montevideo llamada "Nuevos caminos para América Latina"-, cuando sintetizó su reflexión al decir: "Hasta ahora las soluciones para América Latina las han dado los economistas, pero esa vía desarrollista parece detenida. Los políticos hemos de intervenir. Se necesita un desbloqueo político". Tal parece que ya se observa una réacción en contra del determinismo economicista de la lógica ciega del neoliberalismo de la economía globalizada, y que por fin habrá participación en las decisiones a la razón social.

También es interesante que en México los empresarios sean quienes cuestionen la política económica del gobierno (igual que nuestros agricultores). Es decir, las críticas ya no son privativas de la izquierda a la cual se le ha llamado populista, utópica o carente de propuesta por los técnicos, mismos que se empeñaron en el sostenimiento de los indicadores económicos aun a costa de la inversión productiva del desempleo y de la que llaman desaceleración. Así, se atienden, antes que nada, los signos de la macroeconomía postergando al ignorarlos, los que en verdad interesan a la población.

Hemos mencionado implícitamente las izquierdas y las derechas. Por tanto, es oportuno recordar - como nos lo señala Norberto Bobbio en su ya clásico Derecha e Izquierda- que el uso de esas dos palabras se remonta a la revolución francesa, y después - como dice Fernando Savater - de la caída del muro de Berlín y el patético final de los régimenes comunistas, la izquierda ha quedado desconcertada en todos los países, y señala: "Algunos afirman que ya no puede hablarse de izquierda ni derecha y que sólo cabe un pragmatismo político universal". Y agrega: "Sin embargo, esos términos que han orientado a tantos durante un par de siglos se resisten a ser enterrados: ya no son dogmas ni banderas, pero pueden seguir determinando ideales de acción política". Es que no es el fin de la historia, como dijo aquel oriental despistado.

Norberto Bobbio -en su conocida obra mencionada- señala: "Siempre me he considerado un hombre de izquierda y por lo tanto siempre he dado 
al término 'izquierda' una connotación positiva, incluso ahora que está siendo cada vez más atacada, y al término 'derecha' una connotación negativa, a pesar de estar hoy ampliamente revalorizada" (Op. cit., Taurus: Madrid, 1995, 2a. Edición). No hace falta que mencione mi coincidencia con ese juicio, y pensamos así, aun cuando ahora algunos de izquierda comparten y defienden los dogmas y las reglas de la moderna economía de mercado. Estos son aquellos que - según la feliz definición de Heinz Dietritch- representan a la reciente conversión de la izquierda neoliberal.

Gunther Grass señala —en una reciente entrevista publicada en El País (Edición internacional, 17 de noviembre de 1997, pp. 6 y 7)-al referirse a muchos intelectuales de izquierda que él estuvo enfrentando y que apoyaron durante mucho tiempo y sin crítica alguna (son sus palabras) al sistema comunista "con la caída del comunismo se desmoronó su posición y hoy -los conozco bien en Alemania dice- algunos aun totalmente estanilistas hace sólo 20 años se han ido completamente a la derecha. Nada me da más miedo en esta vida que esos conversos". Siempre observamos con escepticismo, y a veces hasta con incredulidad, esa combinación de neoliberalismo de la economía de mercado del capitalismo salvaje con la democracia pluralista. Si ésta funciona de verdad, las mayorías no pueden aceptar un sistema de organización económico en el que resultan perjudicados. Por ello tarde o temprano se verán forzados a revisar los conceptos que se concretan en los que ahora no son directrices o puntos de vista sino dogmas. Esto es consecuencia de la tensión genenerada entre dos principios de organización. La democracia con el sufragio universal, por un lado, y el mercado regido por un sistema donde la apropiación de bienes es proporcional a los recursos de cada uno, por el otro. De esa simbiosis resulta que el neoliberalismo, lejos de conducir al pueblo a una democracia en donde éste tome sus decisiones, se convierte en un régimen manejado por una minoría que se aprovecha de las ventajas del omnipotente mercado.

Arthur Schlesinger Jr. —x asesor del presidente Kennedy - en un reciente artículo titulado “¿La democracia tiene futuro?” (Archivos del Pre-

sente, No 10, octubre-diciembre, 1997, p. 29 y ss.) nos recuerda que Isaiah Berlin decia que éste era "el siglo más atroz de la historia de occidente". Sin embargo - dice Schlesinger-, "este terrible siglo tiene $\longrightarrow$ parece tener- un final feliz". Y agrega: "A medida que el siglo se acerca a su fin, los dos principales villanos han perecido, el fascismo de un golpazo y el comunismo lloriqueando". Pero el señalamiento de Schlesinger que deseamos destacar es el siguiente: "Entendamos cual es la relación entre capitalismo y democracia... el mercado capitalista no es garantía de democracia, como Deng Xiaoping, Lee Kuan Yen, Pinochet y Franco, y desde ya Hitler y Mussolini, lo han demostrado con creces. La democracia requiere del capitalismo, pero el capitalismo no requiere de la democracia al menos en el corto plazo".

El párrafo siguiente del distinguido historiador 
es muy significativo: "...incluso los principales capitalistas están atónitos ante lo que el capitalismo lugitivo ha forjado. Si el entendimiento del capitalismo se puede medir a través del éxito en hacer dinero a partir de él, nadie comprende mejor el capitalismo comtemporáneo que el financista y lilántropo George Soros. 'A pesar de que he hecho una forluna en los mercados financieros' -escribe Soros- 'Ahora me temo que la intensificación sin trabas del capitalismo basado en el dejar hacer y la expansión de los valores del mercado hacia todas las esferas de la vida está poniendo en peligro nuestra sociedad abicrta y democrática'. 'La búsqueda desinhibida del propio interés' - prosigue Sorosda como resultado "inequidades y una inestabili(lad intolerables'...". No hace falta agregar nada.

En este período que llaman de transición, hay quienes preguntan: ¿Podrá la izquierda tradicional, que parece llegar al poder, cumplir lo que esperan los votantes de ella? Y nosotros preguntamos: ¿qué harán los votantes? ¿Buscar soluciones autoritarias? ¿Es que no hay otra cosa? Así lo planteaba Ralph Dahrendorl, entonces decano del St. Anthony's College de Oxford. Pero también hay que preguntarnos ¿.podríamos alirmar que tenemos una nueva derecha, capaz de aceptar las reglas democráticas? Es decir, el respeto a los límites impuestos por el sistema democrálico. La reciente experiencia de la década aclual nos obliga a señalar que no se trata de ignorar, despreciar y humillar a quienes no comparten, aceplan o aguantan - para decirlo en salvadorcño- las políticas cconómicas que han impuesto para beneficio de unos pocos. Se trata de algo más. Esas políticas que estamos viendo ( ¿o suliriendo?) no son maldiciones naturales... Se puede actuar sobre ellas, pero debemos reconocer que se liala de un problema común, esto es, general. Y antes de que todos seamos perdedores, hay que estar conscientes de que la modernización, la globalización, la privalización y todo lo que se llama neoliberalismo, tambićn tiene consecuencias negativas, inconvenientes perjudiciales, etc. para muchos, lo cual debe ser motivo suficiente para reexaminar lo que se ha hecho y buscar correctivos antes que sea muy larde y nos lamentemos despućs de no haber hecho nada.

Es obvio que no podemos negar la existencia de la globalización, pero del mismo modo no podemos ignolar sus derivaciones negativas o sus aspectos más inquictantes. como es la duda sobre su compatibilidad con la profundización de la demo- cracia, cuando un gobierno es impotente para proteger a la nación de los comportamientos de millones de dólares que se desplazan en su contra y alteran la normalidad de cualquier país. Por eso mueve a la reflexión lo que decía George Soros: "Los mercados votan cada día, obligan a adoptar medidas ciertamente impopulares pero imprescindibles. Son los mercados que tienen sentido de Estado".

Cuesta creer lo que estamos viendo, pero hay que verlo para determinar las hondades de la globalización y así considerar como se ha señalado: la competitividad de las empresas, el empleo de los asalariados y el Estado de bienestar de todos. Si uno se desequilibra en detrimento de los otros, la crisis aparece. Sería interminable referir las serias limitaciones, cuestionamientos, consecuencias e inconvenientes de las políticas neoliberales. Las manifestaciones, en ese sentido, son abundantes, repetidas, gencralizadas e incuestionables y únicamente esperamos confiados en los obligados y necesarios reajustes que deberán hacerse en un futuro que esperamos no esté lejano.

Las pretendidas justificaciones para la extensión y amplitud de la autonomía del Banco Central se quieren sustentar en consideraciones económicas, pese a que no se trata de una cuestión de naturaleza económica, pero si se enfoca así es con el deliberado e interesado propósito de ignorar la naturaleza jurídica del problema, que es la primera y obligada aproximación a su estudio. Sólo así nos explicamos lo que se gasta en propaganda para convencernos de un supuesto bienestar económico, olvidando que es la generalidad la que está sufriendo día a día el detcrioro de la situación económica.

Es preciso dejar claro que nuestro único interés ha sido el estudio jurídico de un problema jurídico y la vigencia efectiva de los valores y principios de nuestra Ley Superior. Una vez dijimos que las palabras nos salen solas; ello explica el tono y empleo de términos, expresiones y calificativos a que nos obliga la prepotencia, la ignorancia y, más que todo, la costumbre generalizada de muchos funcionarios públicos en la presente década de ignorar cualquier punto de vista distinto de los dogmas que determinan su forma de actuar.

Cabe señalar que la abundancia de referencias no obedece a un afán de mostrar una erudición, se trata de una costumbre que quedó arraigada después de muchos años de docencia universitaria para 
facilitarles la consulta a quienes obligadamente debían leer lo que yo escribía. De igual modo, hemos tratado que nuestros estudios versen y concentren su enfoque en el Derecho Positivo de nuestros países, por tal razón, nos referimos reiteradamente a los preceptos de nuestros ordenamientos jurídicos particularmente constitucionales. Pensamos así, porque gran parte de lo que ha sido de interés en nuestros estudios ha sido analizado con un alto nivel científico en otros países, por tanto, nuestros aportes no podrían tener un ámbito de validez más amplio.

También hemos citado voces autorizadas que hacen planteamientos, cuestionamientos, críticas, etc. sobre el problema estudiado, con el propósito de diseminar, divulgar respuestas tal vez desconocidas o poco asequibles a la generalidad. Por ello también hacemos referencia a las publicaciones de los medios de comunicación nacionales porque podrían haber pasado desapercibidas o sea necesario reiterarlas dado su interés o importancia.

En los cuatro parrafos anteriores se ha tratado de caracterizar el temperamento, la tónica, la orientación y los propósitos de esta temática. No pretendemos ser dueños de la verdad, pero nos sentiremos sobradamente satisfechos si a partir de su lectura surgiera un interés por profundizar en los problemas importantes del país.

Pues bien, ante planteamientos como el nuestro, nos cuesta creer que se invoque el Convenio con el Fondo y sea motivo de preocupación de los funcionarios y, lo más grave, se utilice para presionar a la Asamblea Legislativa en la aprobación del presupuesto. Estábamos corrigiendo pruebas pero tuvimos que agregar el párrafo siguiente que apareció en las increibles declaraciones del Banco Central (La Prensa Gráfica, 5 de enero de 1998, pp. 12 y 13). Decimos increíbles porque cuando se afirma que "lo adecuado sería que no existiera ninguna exención y que todos los productos y servicios estuvieran agravados", refiriéndose a las exenciones del IVA en el caso de los productos de la canasta básica, como granos, azúcar y lácteos, entonces, quienes conocemos, sabemos y hemos estudiado el IVA sólo podemos decir: los comenta- rios sobran, igual que lo que pueda decirse sobre el resto de la entrevista.

Incluso, también están demás los comentarios, planteamientos y la relación de otras opiniones a las que hacemos alusión. Pensamos así cuando recordamos las palabras de un gran constitucionalista español -Francisco Rubio Llorente- en su artículo "Bonjour tristesse", que tituló así porque señaló que para lo que quería decir no se le ocurría otro mejor. El profesor puntualizó: "Vivimos tiempos de ceniza y penitencia. Guiados fieramente por un Gobierno, que como el que le precedió... no parece tener otra alternativa, los españoles nos preparamos a un esfuerzo suplementario de austeridad". Inevitablemente nosotros hemos pensado algo parecido y tuvimos que recordar otro pais más cercano a nuestros sentimientos, cuando continuamos leyendo al profesor español:

"Se harán menos obras públicas, los funcionarios verán aumentar su sueldo en sólo 1 por ciento (es decir, lo verán reducirse en un 2 por ciento, más o menos, en términos reales) y los asalariados del sector privado irán contra las leyes de la razón y de la historia si pretenden que los suyos se incrementen siquiera en la medida necesaria para que no descienda su poder adquisitivo. Si yo he entendido bien, de los unos y de los otros se espera además que, pese a lo magro de los salarios, consuman más, pues de otro modo no crecerá la economía, y ahorren más para las inclemencias de la vejez. Pero como ambas cosas parecen difícilmente compatibles, quizás yo haya entendido mal y no sean los mismos los invitados a ahorrar y consumir. Quizás esta última tarea no se encomiende a los perceptores de salarios, sino a quienes cuentan con rentas de capital, que, como es bien sabido, no pueden ser limitadas sin grave daño en este mundo de mercados mundializados. También esto parece, sin embargo, imposible, pues esa curiosa división de tareas nos dejaría en manos de los demagogos. Todo debe ser fruto de mi torpeza económica o de una defectuosa transmisión de los análisis y de las propuestas. No insisto más y vuelvo al saludo a la tristeza".

Es patético y preocupante el parecido con nues- 
tros países e incluso cuando podamos resignarnos, es difícil ignorar que informes del Banco Interamericano de Desarrollo (BID) revelaron que en el lustro 199|-1996, la economía de América Latina y la pobreza crecieron al unísono en un tres por ciento, lo que ha significado llevar 235 millones de latinoamericanos (de un total de 470 millones) a los límites de la pobreza, mientras que el desempleo es superior al 16 por ciento como promedio. Pero si lo anterior no es suficiente, el último informe del Programa de la ONU para el Desarrollo Humano (PNUD) presentó las cifras siguientes: el 24 por ciento de la población de América Latina y el Caribe vive con menos de un dólar diario; 11 de cada 100 no llegan a los cuarenta años; 55 millones no tienen acceso a los servicios de salud y 110 millones, al agua potable.

Sin embargo, y a pesar de que no es mucho lo que falta, no queremos recordar esta década - como decía alguien que ya he olvidado quien era- como "tiempo de tránsito y agonía, los años noventa son túrbidos y cenicientos, malos para el sosiego y la memoria, indigos del afecto y acaso del recuerdo". Por eso leímos con esperanza lo que escribió Schlesinger a quien citamos antes: “... pero la ideo- logía del dejar hacer tal vez decaiga a medida que los capitalistas descubran la gama de problemas que el mercado redimido no puede solucionar o que empeora". Este planteamiento podría llegar a ser - antes de lo que pensamos - una realidad, cuando escuchamos el categórico señalamiento de Juan Pablo II en La Habana:

"Por otro lado, resurge en varios lugares una forma de neoliberalismo capitalista que subordina la persona humana y condiciona el desarrollo de los pueblos a las fuerzas ciegas del mercado, gravando desde sus centros de poder a los países menos favorecidos con cargas insoportables. Así, en ocasiones, se imponen a las naciones, como condiciones para recibir nuevas ayudas, programas económicos insostenibles. De este modo se asiste en el concierto de las naciones al enriquecimiento exagerado de unos pocos a costa del empobrecimiento creciente de muchos, de forma que los ricos son cada vez más ricos y los pobres cada vez más pobres. Para muchos de los sistemas políticos y económicos vigentes el mayor desafío sigue siendo el conjugar libertad y justicia social, libertad y solidaridad, sin que ninguna quede relegada a un plano inferior". 